\title{
Analysis on obstacles hindering Textile ERP implementation
}

\author{
R.Surjit ${ }^{1}$ \\ $\left\{\right.$ rst.fashion@psgtech.ac.in $\left.{ }^{1}\right\}$ \\ Department of Fashion Technology, PSG College of Technology, Coimbatore, India ${ }^{1}$
}

\begin{abstract}
Enterprise resource planning (ERP) software is being used in textile and apparel companies for decades. The ERP software to be ready for usage involves various steps like evaluation, selection, negotiation, implementation and post implementation. All these processes have to be carefully handled to avail the complete benefits of using the ERP system. Although, all the above said processes are important to successful ERP usage, implementation process plays a major role as it makes or breaks the usage of ERP system. There are many companies which have removed the ERP system implemented in their company after three years due to issues in the system which were not taken care during implementation and its continued presence. Hence, proper care should be taken during the implementation process. There are various obstacles faced during implementation of ERP in a textile industry. In this study, an attempt is made to find the various obstacles that hinder implementation and then find the reasons for the obstacles. It was found that the obstacles can be classified as employee based, company based, top management based, vendor based and cost based. The critical finding from this study is that vendor based issues play a significant role in the ERP implementation processes delay. There is also equal contribution from company and top management in ensuring smooth implementation. The employee related issues are explained and solutions for taking care of that are provided. The cost based issues are highlighted and ways to minimize the issues are detailed. This study gives a clear idea that coordination at all levels by all stakeholders are required for a smooth ERP implementation process so that the benefits of ERP can be used in a longer run thereby leading to improved efficiency and productivity of a textile and apparel company.
\end{abstract}

Keywords: ERP, Textile, Apparel, Software, ERP Implementation.

\section{Introduction}

Sustainable businesses are the requirement today and for a business to be sustainable in a longer run, it requires processes to be ably controlled and managed. Such controlling and managing can be done with the help of enterprise resource planning (ERP) software. An enterprise resource planning software is an integrating real time business application software which has many modules and a common database [1]. It supports the core functions of an organisation. It is a single software that gathers data of the entire business in a single database using a single application [2]. ERP software consists of various modules. These modules are categorized based on the activities done in an individual department of a company. For example, there will be a sales module in which all the activities of sales department will be 
entered like quotation, sales order, sample development, costing, etc. Similarly there are various modules in an ERP system.

The modules are categorized as technical and commercial modules. The various commercial modules in ERP are sales module, purchase module, inventory module, human relations module, CRM module, finance module, utilities module, asset management module and raw material management module. The technical modules are planning module, production module, quality module, maintenance module, time and action planning module, etc., [3]. Under each module, there will be module specific masters, transactions and reports. Masters are the data that are created for which transactions will be done. For example, in inventory module, material master will be created where all the material details of the company will be entered once while initial software deployment or whenever a new material is to be purchased. There are various other masters created in an ERP software like company master, business unit master, date master, currency master, customer master, supplier master, employee master, unit of measurement master, machine master, etc. The transactions are the real time activities carried out in a module. For example, preparing a store indent is a transaction. When the store indent is prepared in ERP under inventory module, the requested material is selected from the material master and required quantity is entered and submitted. This is how master data is used in a transaction. Based on the transactions entered, various reports can be generated in an ERP software. The reports can be configured by the users or they can use the standard reports provided by the software developer. Many times, the users want reports customized as per their company requirement. It is possible in an ERP system. The reports can be obtained in excel, word or pdf format. There are various types of reports that can be obtained in an ERP software. Some of the reports that can be obtained are Sales report, production report, invoice, purchase order, sales order, request for quotation, store indent, return note, issue note, etc. There can be informational, transactional, analytical and routine reports generated using an ERP software.

The ERP software is provided by many companies. Some of the main ERP providers for textile and apparel industry are SAP SE, Infor, FDM4, Oracle Netsuite, Epicor, SAGE, Ramco, Datatex, Intex, A2000, Polygon, Apparel connect, Kalsofte, Axon, etc.[4,5,6]. These ERP software providers have various module and they can be customized for textile and apparel industry. There are textile and apparel industry ready software also. There are also software developed in house by many companies like Raymonds, Aditya Birla, etc. These software are classified based on their expertise and also as Tier I, II and III. Based on the features and expertise, the cost of these software vary. In today's context, having an ERP system has become mandatory for every company as it benefits the company to a very great extent. The various benefits obtained because of using ERP are a. Getting real time data without any delay, b. It helps in taking operational decisions quickly, c. More visibility is obtained with respect to the processes and products, d. Increased interface with customers and suppliers, e. Material ordering has become easy, f. Order tracking and execution has become simpler, g. Customer promises can be kept up, h. Inventory costs can be reduced, i. More scope for decision making, j. Ease of doing business globally and across many verticals, etc. These are just some of the benefits and the list is endless as there are lots of advantages derived by a company because of implementing ERP. Most of the textile and apparel companies have implemented an ERP system. Some examples of companies who have implemented ERP in India are Aditya Birla, Raymonds, Reliance, Welspun, Premier mills, Mandhana Industries, DCM, Vardhman, Trident, Kitex garments, Arvind brands, etc.

The ERP software selection for a textile or an apparel company is a tedious process. The steps in selection are very intricate and due caution has to be exercised in selecting the right 
ERP. The process of selecting ERP is detailed by Surjit et. al. in their book [3]. It involves evaluation based on features, cost, implementation time, changes required, customization timelines, training period, training resources availability, ease of use, etc. Then it involves the process of choosing the right vendors and comparing the software by having a demo. Then it involves the process of negotiation leading to order finalization and selection of ERP software $[3,7]$. Once the order finalization is done, a business study is conducted to find the requirements of the company by the ERP provider. During this time, the textile or apparel company should do a thorough analysis of the system shown with its features and then propose their requirements to the vendor so that the vendor can develop that for the company. This is a critical stage and any mistake made here leads to lot of problems in the future with respect to implementation and usage of ERP. A business process document is prepared by stating 'AS IS' and 'TO BE' which indicates what is available in the ERP software and what is required in the ERP software respectively [8]. Then the ERP software company develops the requirements and then comes the implementation process.

The timeline of implementing ERP is decided upon based on various factors like number of business units, number of processes, number of modules, number of trainings required, availability of company personnel, etc. The process of implementation is explained to understand the complexities in it. The ERP vendor sends their implementation engineers to do the implementation process. Before the engineers come, the company will be asked to get the masters like material, machine, employee, etc. ready in an excel format or an acceptable format for uploading in to the ERP system during implementation. The company is also expected to get their hardware ready by having the right system configuration for the server including operating system, database which will be mostly Oracle or Microsoft SQL and internet connectivity. The above requirements may also be provided by ERP company if chosen for PaaS or IaaS model which refer to platform as a service and infrastructure as a service model respectively where ERP provider gets all the infrastructure required. There will be a team in the textile or apparel company consisting of IT personnel and people from different departments and they will coordinate all the implementation activities. The engineer will first install the software in the system and then upload all the masters. Then create transactions and generate reports from it. Then implementation also involves training the end user with all the activities that have to be carried out in ERP. It involves making the end user create master, transactions, generate reports, handle database, manage basic troubleshooting, reports configuration and creation, etc. Once the training is done, then parallel run is started where ERP system will start to work by end users making entries simultaneously along with the system or procedure that the company is already following. This is done to check the reliability of the ERP system as many reports are compared with the legacy system to check for accuracy and error free nature. Once this stage is crossed, the live run is started where the legacy system is replaced and the new system is used by the entire company. The stability and working is checked and a sign off report is obtained by the engineer stating that the ERP implementation is completed. There will always be future support provided for management of ERP system and bug handling using annual maintenance contracts created between both parties. So the above activities are involved in the implementation process. To complete these activities in a textile and apparel company, it takes 2 to 6 months on an average. However, in many cases, it extends to even one year and there are many examples where the ERP implementation was stopped because of many discrepancies.

As indicated above, there are so many activities done in implementation and hence it involves more commitment from all stake holders for successful implementation. However, it is not the case in many textile and apparel ERP implementation and there are lots of 
roadblocks during the implementation. Hence, in this study, an attempt has been made to understand the various obstacles faced during ERP implementation in a textile and apparel industry and the solutions for avoiding the obstacles are also discussed. This will work as a ready reference paper for any company to refer to when implementing an ERP software in their premises in the future.

\section{Materials And Methods}

The entire study was done by collecting data by two methods. One, the implementation process obstacles were studied by referring to content available online. It involved searching various research and publication database like Springer, Elsevier, Research gate, Scopus. Also Google search and Google scholar was used and information was collecting using search phrases like 'ERP implementation obstacles, implementation challenges, hindrances of ERP implementation in textile and fashion industry, ERP implementation shortfalls in textile and apparel, complexities in ERP implementation in textile and apparel'. It was found that the research with respect to the implementation process in a textile and apparel company is very limited. Hence, the next method was also used to collect the data. It involved getting in touch with apparel and textile companies in and around Coimbatore, Tirupur, India and conducting unstructured interviews with the stakeholders of ERP in the company on the obstacles and hindrances faced during ERP implementation. Similarly telephonic conversations were carried out to get the data from companies in other parts of India on the issues faced by them during the implementation. Based on the data gathered through these two methods, the analysis was carried out to understand the problems and then arrive at solutions to the specified problems.

\section{Results And Discussions}

The data collected was assimilated and the obstacles faced during ERP implementation were found. The obstacles were not limited to the vendor alone and hindrance was there for the vendor which includes software developers, testers, implementation engineers; employees of the company implementing ERP, middle management of the company, top management or owners of the company.

The various obstacles or challenges faced by vendor and company are high implementation costs, lack of IT infrastructure [9], low interest level of employees, initial wrong judgment by top management about the boundary of ERP [10], differences in business process between different units of a company (heterogeneous nature), ERP system incompatibility, troublesome migration, employees resistance to change, lack of collaboration and co-operation from employees [11], failure to establish metrics [12], unrealistic expectations, poor project management [13], frequent changing of end user requirements [14], lack of incentives to employees for implementing ERP [15], under estimation of time and resources during implementation, enough data not provided by the company, no cooperation during training, business philosophy differences, lack of top management support and problems in integration with other software like PLM, CRM [3] and lack of domain knowledge of implementation engineers and software developers. The above are the major reasons provided for hindrances in ERP implementation. These obstacles can be grouped into 
employee based, company based, top management based, vendor based and cost based issues. The obstacles and their solutions are discussed below:

\section{Employee based issues}

The employee based issues are employees' resistance to change, low interest level of employees, lack of collaboration and co-operation from employees.

The employees have a great resistance to change. This is because they do not know the benefits of ERP and they fear that it will lead to more work, more efforts, more time involvement. They also feel that it will take away their jobs as computers may replace humans. It is also that their errors may be found out by the system and may lead to reprimanding. Such issues have to be handled well by the management by giving proper education. The employees should be called for a meeting and they should be explained about the advantages of having an ERP system. Any fears noticed should be addressed and employees should be comforted that their jobs are not in danger. A clear picture should be given on what is required from employees and how they can assist during ERP implementation. Every employee in the company should know about the implementation and its benefits. The employee should be motivated to increase their interest levels, they should be explained about how time will be saved because of using the ERP software. The employees will be having their regular work and if ERP implementation is thrust on them as an additional work, they will feel burdened and so there will be less cooperation and collaboration from their end. So it should be ensured that the workload of employees is properly managed so that it doesn't lead to fatigue.

\section{Company based issues}

The company based issues are lack of IT infrastructure, differences in business process between different units of a company (heterogeneous nature), failure to establish metrics, unrealistic expectations, poor project management, frequent changing of end user requirements and enough data not provided by the company.

The company issues have to be managed well to ensure the implementation process smoothness. There should be clear understanding on the various IT infrastructure requirements for ERP implementation. While planning for ERP software buying, the company should understand that there are various other costs along with ERP software purchase and they should make proper allocation of cost to accommodate the requirements of the implementation. The server of required specification should be purchased on time. A small team of IT personnel should be recruited to aid the process and also manage the ERP in future. Database licenses should be obtained. Internet connectivity with required bandwidth should be procured.

It is also noticed that the business processes vary between various units of a single apparel company. For example, in one unit, subcontracting may be done and it may need a purchase order raised for it whereas in another unit, there will be no subcontracting. Similarly there can be many differences between the business processes of the company. So the implementation team of the company should clearly identify the differences in each business unit and explain that to the vendor to make suitable changes in the system during process study and not during implementation as that will lead to delay in implementation. Another obstacle is the failure to clearly define the deliverables from the ERP. It has to be checked with the vendor on what are the metrics that will be used to evaluate the ERP after implementation. It should be mutually decided upon, or else, it will lead to unrealistic expectations from the ERP software. The company not having a comprehensive idea on the requirements at early stage will face a problem during implementation. The company should be do a thorough analysis of the software during business process study and specify the requirements clearly. Frequent changes 
in requirements will only delay the process and lead to increased costs. It will also lead to vendor fatigue as it will become impossible for the vendor to satisfy the frequent changes in the requirements. The company should have a proper planning as project management issues surface during implementation. A clear roadmap with deliverables at each stage and time limits should be there to avoid project management issues. The company should spend enough time to have all the data ready like masters, reports required, etc. so that delay can be avoided on that front. Such proper measures will help avoiding company related issues in implementation.

\section{Top level management issues}

The various top level management issues are lack of commitment, under estimation of time and resources during implementation, lack of incentives to employees for implementing ERP, business philosophy differences, initial wrong judgment by top management about the boundary of ERP.

Many owners of textile and apparel companies do not review the ERP software and purchase it due to pressure from the competitors. ERP is not like a readymade product purchase or a computer purchase. It requires more planning and vision. So the top management should understand that purchasing the software alone is not their job and they have to be very committed in ensuring that the ERP system is implemented and used by everyone in the company. Many ERP failures reported are due to lack of top management initiatives. Another issue with top management is that they don't plan for resources required for implementation and time required for it. Unrealistic time schedules and low allocation of resources will only make the process complex and lead to delay in the implementation process. Costs for employee utilisation during ERP implementation should also be studied and money should be allocated for that. If incentives are not provided or additional benefits are not provided to people working on the implementation process, it will lead to employee morale and interest going down, resistance and reluctance of employee will be noticed. Hence, top management should provided incentives and benefits to employees working in the ERP system implementation.

The business philosophy differences also affect implementation. The company may have a different way of dealing a business which may be specific to the area, state, country, culture, people, etc., but the ERP software is made for universal use. So the top management should review the software to understand the differences and may even try to follow the processes suggested in the ERP system as they are developed with universal applicability and are also checked to meet ethical standards. The issue of wrong judgment about what ERP will do by the top management also leads to issues. The management should know the boundary of ERP, which means the areas, processes and levels covered in ERP. ERP may not cover SCM, CRM, BI, PLM, etc. and the company should know that initially to avoid issues during implementation.

\section{Vendor based issues}

The vendor based issues are problems in integration with other software like PLM, CRM, ERP system incompatibility, troublesome migration, lack of domain knowledge of implementation engineers and software developers.

Many times, it is wrongly portrayed that the fault of delay in implementation is due to the apparel or textile company. Actually, it is not so all the time and it is also based on the vendor to a great extent. The lack of domain knowledge of the vendor plays a major role in implementation. This issue is faced many times during textile and apparel company implementation. The implementation engineer may be a software professional and would not understand the complexities or requirements of textile and apparel ERP processes and 
procedures thereby leading to conflicts during implementation. In some cases, the implementation engineer would have domain knowledge, but the understanding of the software development team about the requirements proposed by him or her would be very low and it leads to wrong development thereby increasing the implementation time. The vendor should have a clear vision on the software perimeter and verticals it has to address and act accordingly. The vendor should make sure that the software is compatible for integration with other software like PLM and CRM. If not, it has to be told to the client during ERP selling time. The incompatibility, if any with other legacy systems of the client should be checked and addressed during business process study time. There should be clear standard operating procedures for data migration from legacy systems as new data creation will take more time and effort. It is required that vendor makes proper planning to avoid delay in implementation.

\section{Cost based issues}

There are cost based issues with respect to ERP implementation. Many companies feel that there are high implementation costs as it involves providing accommodation, food and other requirements for the vendor implementation team. It also involves having necessary IT infrastructure for implementation, more people than earlier for taking care of the system, etc. So in such cases, it should be discussed with the vendor on the costs involved during implementation and plan accordingly. Some vendors charge service charges per day of implementation. So it is not based on a fixed time and it is based on number of hours and days. In that case, the client should ensure that their systems, people and data are readily available so that there is no delay from their side as any delay will lead to increased costs for the company. Actually service charge per day based implementation works well as the client would want to extract more for a day from the vendor and vendor also tries to meet the requirements quickly so that they can complete the implementation and move to the next project. Such arrangements will reduce the cost issues associated with implementation.

The above discussion presents a brief idea and methods to avoid the various obstacles faced by textile and apparel companies during ERP implementation. Proper planning is the key for successful implementation. It is not that ERP implementation is always a troublesome activity. There are numerous companies which have successfully installed ERP and are using it for decades now. It is only that proper management of activities, processes and requirements are required to ensure successful implementation.

\section{Conclusion}

This study details the processes in ERP software usage by a company. It discusses the benefits of ERP software for a textile industry. The various textile and apparel ERP software developers are listed. The steps in getting the ERP ready for usage are listed. The importance of ERP implementation process is detailed and the obstacles faced during the implementation process are identified. Researches done related to obstacles for ERP implementation and unstructured interview with various stakeholders of ERP implemented textile and apparel companies gave the required data for the analysis. The various obstacles for the implementation process were classified under the broad heads as employee based, company based, vendor based, top management based and cost based. It was found that employee based issues were related to resistance to change and company based issues were majorly the different business processes in different units, lack of IT infrastructure. The top management issues involved lack of top management commitment and no clear roadmap for the 
implementation along with no proper planning. The vendor based issues were very prominent as they involved lack of expertise at their end to have an industry ready product. The cost based issues were due to improper planning before start of implementation and not having a clear idea on the costs involved for getting required infrastructure including information technology related needs and required manpower. Suitable solutions are discussed and provided for each issue and it is found that proper planning will lead to correct implementation process and avoid delays. It will lead to get the desired benefits from the ERP software.

\section{References}

[1] Stefanou, C.J., 2000. The selection process of enterprise resource planning (ERP) systems. AMCIS 2000 Proceedings, p.418.

[2] Tadjer, R., 1998. Enterprise resource planning. Internetweek, pp.40-44.

[3] Surjit, R., Rathinamoorthy, R. and Vardhini, K.V., 2016. ERP for textiles and apparel industry. CRC Press.

[4] Carlton, R. 2019. Five top apparel ERP systems for your software shortlist, https://www.erpfocus.com/top-apparel-erp-systems.html. Accessed on 20 September 2021.

[5] Anonymous, n.d. Apparel ERP software, https://www.softwareadvice.com/manufacturing/apparelmanufacturing-software-comparison/. Accessed on 20 September 2021.

[6] Anonymous, n.d. Best ERP software for apparel business, https://www.softwaresuggest.com/erpsoftware/apparel-industry. Accessed on 20 September 2021

[7] R.Surjit and K J Vishnu Vardhini, 2014. "Evaluating and selecting the right ERP for a textile business", Asian Textile Journal, pp. 63-66.

[8] Tsai, W.H., Chen, S.P., Hwang, E.T. and Hsu, J.L., 2010. A study of the impact of business process on the ERP system effectiveness. International Journal of Business and Management, 5(9), p.26.

[9] He, X., 2004. The ERP challenge in China: a resource-based perspective. Information Systems Journal, 14(2), pp.153-167.

[10] Mirhosseini, S.S., Azar, A. and Jahanyan, S., 2019. Examining the Risks and Obstacles to the Success of ERP implementation using the Critical System Heuristics (CSH) Approach. Modern Research in decision Making, 4(4), pp.31-58.

[11] Banaeianjahromi, N., Kähkönen, T., Alanne, A. and Smolander, K., 2016, January. Integration obstacles during ERP development. In 2016 49th Hawaii International Conference on System Sciences (HICSS) (pp. 4697-4706). IEEE.

[12] Ross, J.W. and Vitale, M.R., 2000. The ERP revolution: surviving vs. thriving. Information systems frontiers, 2(2), pp.233-241.

[13] Hodge, G.L., 2002. Enterprise resource planning in textiles. Journal of Textile and Apparel, Technology and Management, 2(3), pp.1-8.

[14] Yu, C.S., 2005. Causes influencing the effectiveness of the post-implementation ERP system. Industrial Management \& Data Systems.

[15] Choi, T.M., Chow, P.S. and Liu, S.C., 2013. Implementation of fashion ERP systems in China: Case study of a fashion brand, review and future challenges. International Journal of Production Economics, 146(1), pp.70-81. 